ANNALES

UNIVERSITATIS MARIAE CURIE-SKŁODOWSKA LUBLIN - POLONIA

VOL. LXXIII, 1 SECTIO AA

\title{
Synthesis, properties and applications Of CMK-3-type ordered mesoporous carbons
}

\author{
Rafał Olchowski* and Ryszard Dobrowolski \\ Maria Curie-Skłodowska University, Faculty of Chemistry \\ Department of Analytical Chemistry and Instrumental Analysis, \\ Maria Curie-Skłodowska Sq. 3, 20-031 Lublin \\ *email: rafal.olchowski@poczta.umcs.lublin.pl
}

For the last two decades the CMK-3-type carbon was the subject of study by researchers from all over the world for wide range of applications: adsorptive, catalytic, magnetic and electric. Changing of modification strategies resulted in obtaining carbonaceous materials with interesting properties. In this review the synthesis, properties and applications of the CMK-3-type nanocarbon are described.

Keywords: CMK-3, SBA-15, adsorbents, batteries, catalysts, capacitors, controlled drug release

\section{INTRODUCTION}

A carbonaceous material is defined as a porous solid, which contains cavities, channels or interstices that are deeper than they are wide. These materials can be classified according to the pore widths $(w)$ as [1]:

- microporous $(w<2 \mathrm{~nm})$,

- mesoporous ( $2 \mathrm{~nm}<w<50 \mathrm{~nm})$,

- macroporous ( $w>50 \mathrm{~nm}$ ). 
Among porous carbons there are materials, which have ordered mesochannels, called Ordered Mesoporous Carbons (OMCs). The first synthesis of this kind of nanocarbon (denoted as CMK-1) was reported by Ryoo et al. in 1999 [2]. This group of researchers used an Ordered Mesoporous Silica (OMS) of the Ia3d symmetry (denoted as MCM-48) as the hard template and sucrose as the carbon precursor. However, the structural symmetry of the obtained CMK-1-type carbon changed to a different one than the one produced by the silica template.

In 2000 Ryoo et al. [3] reported the synthesis and characteristics of a new OMC denoted as CMK-3. The researchers used the SBA-15 silica of the $\mathrm{P} 6 \mathrm{~mm}$ symmetry as the template and sucrose as the carbon precursor. For the first time the synthesized carbon was the ideal reverse replica of the silica template. Moreover the carbon nanorods were interconnected by spacers, which consisted of the carbon that filled the channel-interconnecting micropores within the SBA-15 wall. Pristine CMK-3-type carbons characterized by a high BET active surface area (up to $1500 \mathrm{~m}^{2} / \mathrm{g}$ ), hydrophobic surface, chemical stability and ease of surface chemical modifications. Since the first synthesis of this material, research has focused on the chemical surface modifications of the CMK-3-type carbons and their various applications as adsorbents [4, 5], catalysts [6-8], batteries [9$11]$, capacitors [12-14], electrochemical sensors $[15,16]$ or materials used for controlled release of drugs $[17,18]$. In this review the synthesis by the hard-templating route, various surface modifications, physicochemical properties and applications of the CMK-3-type carbons will be described.

\section{HARD-TEMPLATING ROUTE}

The hexagonal ordered mesoporous carbon denoted as CMK-3 can be synthesized by the hard-templating route, also known as the exotemplating (Fig.1.), where a rigid inorganic solid is used as a template to create an another solid confined in its porous network. When the template is removed by an alkali or acid elution of the silica structure, an ordered pore system is developed [19]. 


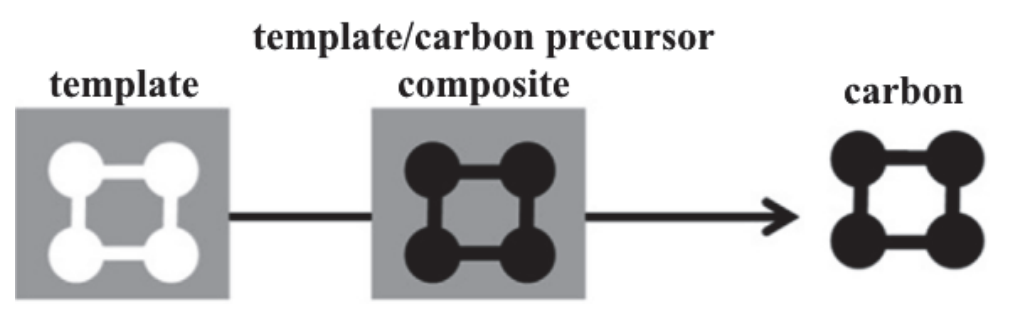

Fig. 1. Scheme of exotemplating strategy [19].

This approach consists of four steps (Fig. 2.) [19]:

- synthesis of the silica template (SBA-15),

- infiltration of the template with a suitable carbon precursor and the subsequent polymerization inside the porous network,

- carbonization of the Si/C composite,

- removal of the template by treatment with an aqueous solution of $\mathrm{HF}$ or an ethanol-water solution of $\mathrm{NaOH}$.

(1)

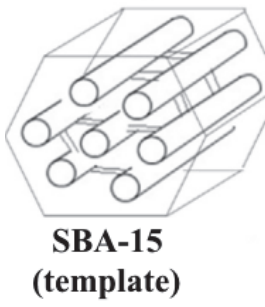

(2)

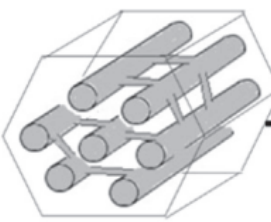

SBA-15 impregnated with carbon precursor
(3)

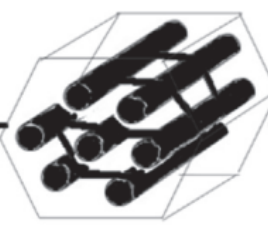

$\mathrm{Si} / \mathrm{C}$ composite after carbonization

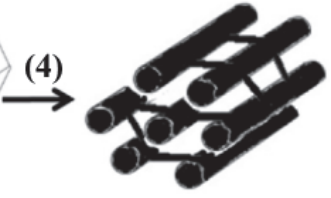

pristine CMK-3

Fig. 2. Scheme of the CMK-3 synthesis ((1)-synthesis of SBA-15 by sol-gel method, (2)-infiltration of SBA-15 with carbon precursor, (3)-carboni-zation of the $\mathrm{Si} / \mathrm{C}$ composite, (4)-removal of the template by $\mathrm{HF}$ or $\mathrm{NaOH}$ ) [19].

\subsection{Synthesis of SBA-15 by sol-gel method}

The SBA-15 silica template can be synthesized by the sol-gel method, also known as the endotemplating (Fig. 3), which consists of occluding atoms, molecules or supramolecular structures in the prepared solid framework [19]. 


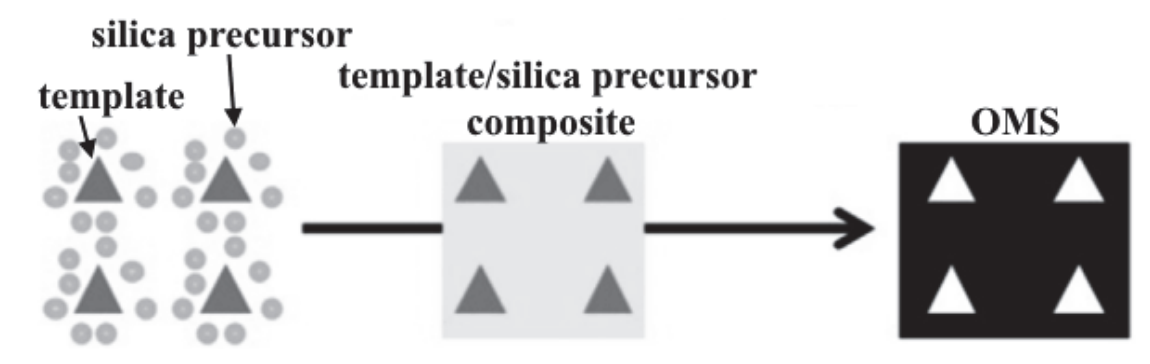

Fig. 3. Scheme of the endotemplating strategy (OMS - Ordered Mesoporous Silica) [19].

Synthesis of the SBA-15 by this route consists of (Fig.4.) [20]:

- self-organization of poly(ethylene oxide)-poly(propylene oxide)-poly(ethylene oxide) (PEO-PPO-PEO) copolymer (often Pluronic123, $\mathrm{EO}_{20} \mathrm{PO}_{70} \mathrm{EO}_{20}$ ) molecules into cylindrical micelles in acidic conditions (e.g. $2 \mathrm{M} \mathrm{HCl}$ ),

- hydrolysis reactions of alkoxy groups of silica monomer molecules e. g. tetraethoxysilane, tetramethoxysilane,

- heterocondensation of alkoxy groups with silanol groups or homocondensation of silanol groups coming from silica monomer onto the liquid crystal template of copolymer (Fig. 5),

- gelation step - sol to gel conversion,

- aging step - the liberation of dispersion center from gel,

- removal of the template by calcination or extraction process,

- drying step - removal of water, ethanol and silica monomer residues.

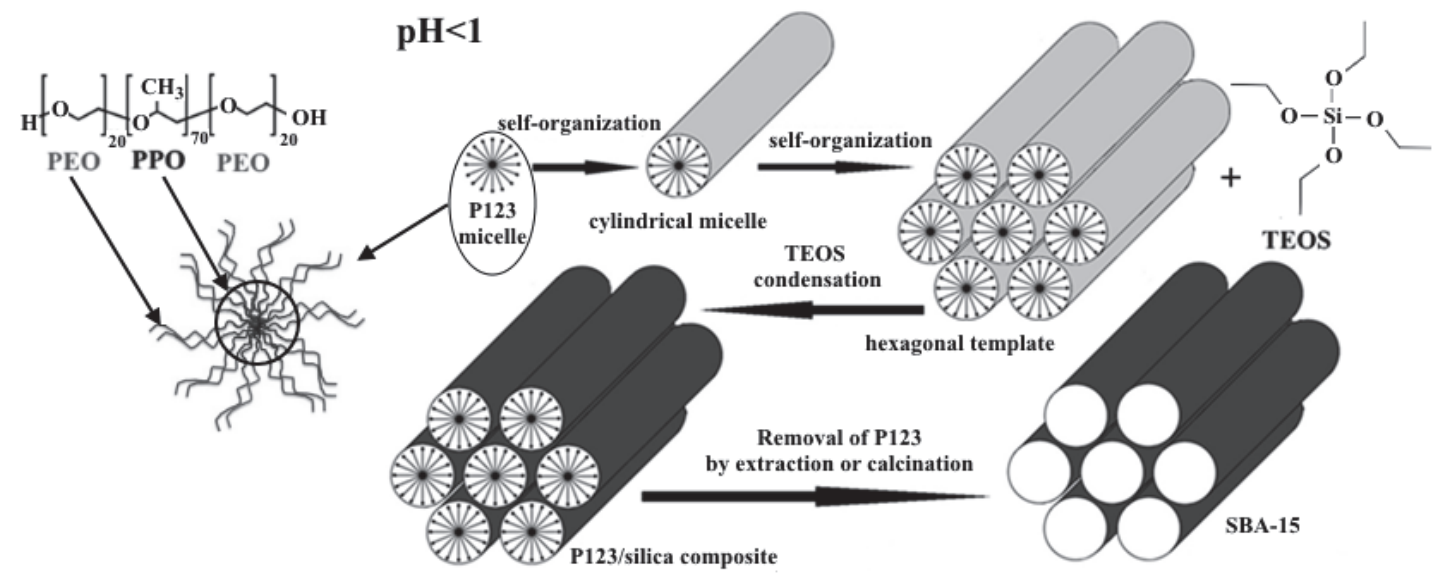

Fig. 4. Scheme of the SBA-15 synthesis by the sol-gel method [20]. 

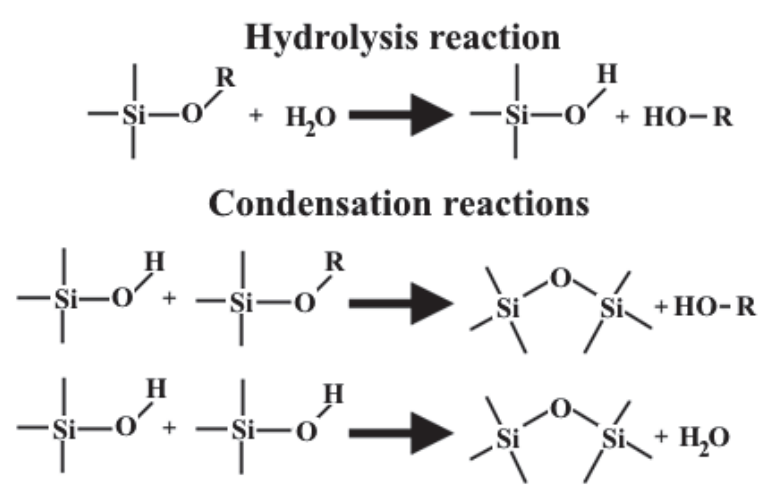

Fig. 5. Reactions occuring in reaction mixture during the sol-gel process (Ralkyl group) [20].

Low $\mathrm{pH}$ of the reaction mixture simultaneously favors the hydrolysis reactions of the silica monomer and inhibits the condensation step, which allows obtaining the product with highly ordered mesopores. The generally used silica monomer during SBA-15 synthesis is tetraethoxysilane (TEOS) [20]. All synthesis conditions (such as temperature and time of P123 micellization and aging steps, concentration of P123 or adding pore expanding agents) influence the porous structure of the obtained product [21]. Highly ordered silica product can be obtained only in the P123 concentration range of 2-6 wt. \%. The temperature of the micellization step is also important and it should be established between $35-80^{\circ} \mathrm{C}$. Moreover, the porous structure of SBA-15 product strongly depends on the aging condition. Zhao et al. [22] synthesized the SBA-15 in different aging temperatures $\left(80-140^{\circ} \mathrm{C}\right)$ and times (11-72 h). They came to the conclusion that an increase of aging temperature and time influenced obtaining silica product of wider mesopores (6.0-8.9 nm) and thinner pore walls (5.3-3.1 nm). Furthermore, an aging temperature above $100^{\circ} \mathrm{C}$ causes gradual vanishing of microporosity. Jana et al. [23] used different types of organic auxiliary chemicals (e.g. methyl-substituted benzenes) to obtain SBA-15 with various pore sizes up to $43.0 \mathrm{~nm}$. Mesopore size of the obtained silica product was dependent on the type and amount of auxiliary chemical.

The pore width of SBA-15 silica can also be adjusted by using other poly(alkylene oxide) triblock copolymers with EO/PO ratio (0.07-1.5). Another way to synthesize the SBA-15-type silica is using 
a triblock poly(alkylene oxide) copolymer with reversed architecture (e.g. $\left.\mathrm{PO}_{19} \mathrm{EO}_{33} \mathrm{PO}_{19}\right)[22]$.

Usually the calcination process aimed at removal of the surfactant is carried out in an air, ozone, oxygen or nitrogen oxide atmosphere at ca. $550^{\circ} \mathrm{C}$. However this process is ineffective and it can lead to the shrinkage of the product structure or its destruction (inorganic framework of product can collapse at this temperature) [20].

The second method for the template removal from obtained composite is the low-temperature extraction with a proper solvent. Extraction methods lead to effective removal of the template without its decomposition and they are eco-friendly [20,22].

SBA-15 is characterized by high hexagonally ordered cylindrical mesopores interconnected by micropores (microporous crown), which are important for stability of the further synthesized carbonaceous product. This ordered mesoporous silica is characterized by an X-ray diffraction technique. 3-7 well-resolved diffraction peaks at low angles (up to $3.5^{\circ}$ ) are related to $\mathrm{p} 6 \mathrm{~mm}$ symmetry. Usually the nitrogen adsorption/desorption isotherm of SBA-15 has a hysteresis loop at higher relative pressures ( $>0.5$ ), which is connected with the capillary condensation process in wide mesopores. SBA-15 is hydrothermally and mechanically stable. The BET surface area of the SBA-15 silica is around $1000 \mathrm{~m}^{2} / \mathrm{g}$, depending on the synthesis conditions. Chemical composition of the surface of SBA-15 can be easily chemically modified by different organic and inorganic modifiers [22].

\subsection{Infiltration of $S B A-15$ by carbon precursor}

The second step of the CMK-3-type carbon synthesis by the nanocasting strategy is infiltration of the porous network of the obtained silica template (SBA-15) by a selected carbon precursor (Fig. 6). The infiltration process can be carried out by two ways: from a liquid phase (impregnation) or from a gas phase (chemical vapor deposition, CVD or vapor deposition polymerization, VDP). Impregnation of the template with a solution of the carbon precursor can be conducted by using an excess (wet impregnation) or equivalent (incipient wetness impregnation) volume of solution to the pore volume of the silica template. Other infiltration processes rest either on the thermal decomposition of an gaseous carbon 
precursor (hydrocarbon) at high temperature (CVD) or on the deposition of a carbon precursor from gas phase at low temperature and subsequent polymerization (VDP) inside the pores of the template. The important factor during the infiltration process is the carbon precursor itself. It must have suitable dimensions and favourable interactions with the silica walls. Moreover, the polymerization step of carbon precursor inside porous network of the SBA-15 may require the presence of a catalyst [19].

\section{Carbon precursors}
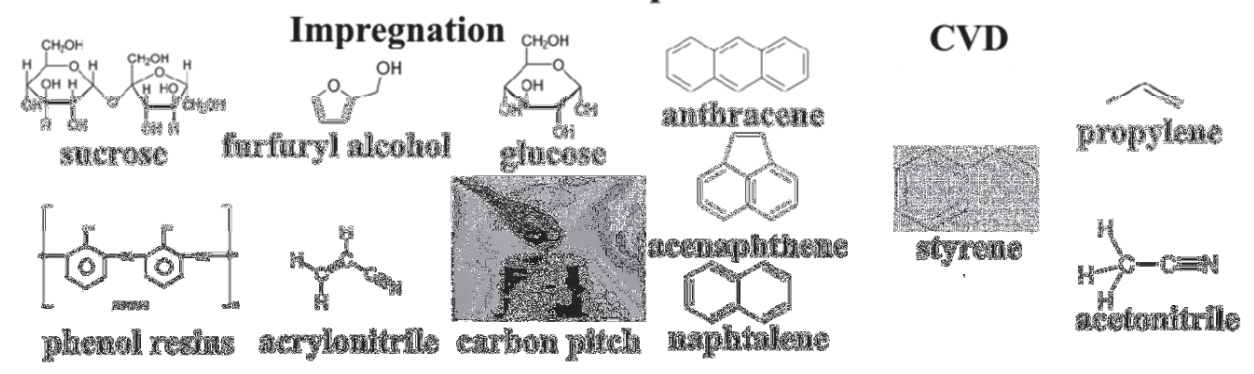

Fig.6. Examples of carbon precursors used in nanocasting strategy [19].

The first method of impregnation of the SBA-15 was proposed by S. Jun et al. [3] in 2000 by using of an aqueous solution of sucrose and $\mathrm{H}_{2} \mathrm{SO}_{4}$, which acted as the catalyst of sucrose polymerization.

It is worth mentioning that other research groups also used sucrose as the carbon precursor during the CMK-3 synthesis [24-28]. C. Weinberger et al. [29] proposed new CMK-3 synthesis conditions. The fructose was mechanically ground with SBA-15 and the obtained mixture was heated. On the other hand K. P. Gierszal et al. [25] and T.-W. Kim et al. [30] used furfuryl alcohol as the carbon source and SBA-15 containing Al (Al-SBA-15) in its structure both as a template and catalyst of furfuryl alcohol polymerization. Infiltration of furfuryl alcohol was carried out at room temperature, followed by two-step polymerization. Another research group (P. Niebrzydowska et al. [31]) used $\mathrm{HCl}$ as catalyst in order to induce furfuryl alcohol polymerization inside SBA-15 pores. Oxalic acid acted as another type of catalyst of furfuryl alcohol polymerization inside a porous network of a silica template during synthesis of the CMK-3 carbon material described by Y. Zhai et al. [24] and A. Węgrzyniak et al. [28]. Naphthalene and anthracene were other interesting carbon precursors infiltrated into template pores. The naphthalene or 
anthracene with acetone and sulfuric acid were infiltrated into the SBA-15 template at room temperature under stirring, then partially pyrolyzed in the atmosphere. Next, the resultant composites were heated under a nitrogen atmosphere [24]. The approach proposed by K. P. Gierszal et al. [25] gained attention because they obtained the reversed replicas of SBA-15 by using acenaphthene, mesophase pitch or petroleum pitch as the carbon precursor. First acenaphthene was mixed with Al-SBA-15 and then the mixture was heated in a muffle furnace. SBA-15 impregnation by mesophase pitch (based on naphthalene or methyl naphthalene) or petroleum pitch was based on mixing silica with a proper carbon precursor and ethanol. After evaporation of ethanol the mixture was heated in a quartz reactor at $30^{\circ} \mathrm{C}$ above the softening point of pitch. K. Wu and Q. Liu [32] incorporated glucose into the porous network of the SBA-15 silica template using the above mentioned conditions [3]. J. Kim et al. [26] used SBA-15 silica modified by cobalt ions (Co-SBA-15) as a template and phenolic resin as a carbon precursor. Phenol infiltrated the Co-SBA-15 pores under static vacuum during heating and it was subsequently polymerized in the presence of formaldehyde. Y. Wang et al. [33] used soybean oil as carbon precursor for impregnation of SBA-15 material. Their impregnation method was based on grinding silica template with soybean oil at room temperature.

X. Wang et al. [34] mixed SBA-15 with an ethanol/water $(\mathrm{v} / \mathrm{v}$, 1:1) solution of raffinose. The obtained paste was cured at proper time-temperature conditions for the solidification of raffinose inside the pores of the template. M. Baikousi et al. [35] filled the pores of SBA-15 by acetylenedicarboxylic acid using $\mathrm{H}_{2} \mathrm{SO}_{4}$ as catalyst and used similar conditions to that described by Jun et al. [3]. M-diethynylbenzene (m-DEB) was used by B. Zhang et al. [36] for the first time as a precursor in the synthesis of CMK-3 via the wet infiltration method. The mixture of m-DEB and SBA-15 was treated by the suitable time-temperature program before carbonization.

Á. Sánchez-Sánchez et al. [37] infiltrated the pores of the SBA-15 template by propylene using the CVD method. The SBA-15 silica placed in tube furnace was treated with Ar saturated with propylene at high temperature for few hours. Y. D. Xia et al. [38] applied the CVD method for infiltration of the SBA-15 by styrene or acetonitrile.

A. B. Fuertes and D. M. Nevskaia [39] proposed a new infiltration method of the SBA-15 by furfuryl alcohol, called vapor deposition polymerization. Firstly they impregnated the template with 
p-toluenesulfonic acid. Then a stream of nitrogen saturated with furfuryl alcohol was passed through the SBA-15 at room temperature for 7 days. After that the polymerization process of the carbon precursor inside silica pores at higher temperature was conducted.

\subsection{Carbonization of Si/C composite}

The next step of the CMK-3 synthesis is carbonization (pyrolysis) of the infiltrated carbon precursor inside the porous network of the template.

This process is performed in an inert atmosphere $(\operatorname{Ar}[27,33$, $40], \mathrm{N}_{2}[26,29,31]$, vaccum $\left.[3,25,30]\right)$ at high temperature (700$1100^{\circ} \mathrm{C}$ ) for a few hours, in a tubular furnace.

\subsection{Leaching of silica template}

Removing of the silica template is the last and crucial step in the synthesis procedure of CMK-3-type carbon. Pores of the reversed carbon replica released in this step become available. In the literature it is usually mentioned about the procedures using an aqueous solution of $\operatorname{HF}(5$ wt. \% [3, 29], 10 wt. \% [26, 28], 40 wt. \% [27]) or a water-ethanol ( $50 \mathrm{vol}$. $\%$ of water and 50 vol. \% of ethanol) solution of $\mathrm{NaOH}$ (e. g. $1 \mathrm{M}[3,40]$ ) for this purpose.

D. K. Singh et al. [41] proposed an innovative method for silica template removal. They mixed the $\mathrm{Si} / \mathrm{C}$ composite with teflon powder before the carbonization step. The obtained CMK-3 nanocarbon had a high surface area $\left(2545 \mathrm{~m}^{2 \cdot} \mathrm{g}^{-1}\right)$ with significant microporosity. The researchers not only shortened synthesis time by combining silica removal and carbonization in a single step, but also eliminated usage of corrosive HF.

\section{MODIFICATIONS OF CMK-3-TYPE CARBON}

The surface of nanocarbon denoted as CMK-3 can be modified during synthesis or by post-synthesis strategy using various organic or inorganic compounds. This kind of carbonous materials can be also modified by increasing the graphitization degree of the nanorods, changing the morphology of carbon nanoparticles or developing a carbonaceous porous structure. 


\subsection{Chemical surface modifications}

\subsubsection{Modifications during carbon synthesis}

Modifications during carbon synthesis are based on incorporation of heteroatom/s such as N, O, P, S, B mainly into graphitic layers of carbon or metal species onto the surface of carbonaceous material. In the first case

a carbon precursor or SBA-15 silica with heteroatom/s can be used. In the second instance solutions of inorganic salts of metals are used.

\subsubsection{A carbon precursor with heteroatom/s and modified SBA-15}

So-called 0-doped CMK-3 nanocarbons were obtained by different research groups by using already mentioned carbon precursors: sucrose [3], fructose [29], glucose [32], furfuryl alcohol [31], phenolic resin [26], raffinose [34], polyethylene glycol 400 [42] or acetylenedicarboxylic acid [35]. Nitrogen was introduced into graphitic planes of CMK-3 carbon by using acetonitrile $[43,38]$, acrylamide [44], pyrrole [45], functionalized ionic liquids [46], ethylenediamine dissolved in $\mathrm{CCl}_{4}$ [47-49] or SBA-15 modified by 3aminopropyltrimethoxysilane with sucrose [13]. CMK-3 doped with nitrogen and oxygen were synthesized by using different amino acids [50], m-aminobenzoic acid [51], d-glucosamine hydrochloride [32] or hexamethoxymethyl-melamine [52]. In the literature there are also described synthesis conditions of reversed carbon replicas of SBA-15 containing in its graphitic layers nitrogen and sulphur (pyrrole and thiophene [53], pyrrole oligomer and $\mathrm{H}_{2} \mathrm{SO}_{4}$ [54]), sulfur and oxygen (furfuryl mercaptan [11]), sulfur, nitrogen and oxygen (ionic liquids and sulfonic acid [55], acrylonitrile telomer [56]), phosphorous, oxygen and nitrogen (phosphoric acid and pyrrole [14]) or boron and nitrogen (dimethylaminoborane [57]).

\subsubsection{Metal species}

S.-H. Liu et al. [58] embeded platinum nanoparticles into CMK3 carbon by using a mixture of platinum acetylacetonate, furfuryl alcohol, trimethylbenzene and oxalic acid for impregnation of a nitrogen-modified SBA-15 template and subsequent temperature treatment. Other research groups [59] synthesized Ru-CMK-3 carbon by impregnation of pristine or S-modified SBA-15 silica with $\mathrm{RuCl}_{3}$ and sucrose. Nickel nanoparticles were incorporated into CMK-3 porous structure by P. F. Fulvio et al. [60]. They used 2,3- 
dihydroxynaphthalene as carbon precursor, SBA-15 as a template and nickel nitrate hexahydrate solution in 2-propanol as the nickel source, which was added to the carbon-silica nanocomposite prior to thermal treatment.

Some researchers published papers describing synthesis of CMK-3-type carbon with magnetic properties. This approach is based upon impregnating SBA-15 material by the mixture of a carbon precursor with $\mathrm{Fe}\left(\mathrm{NO}_{3}\right)_{3} \cdot 9 \mathrm{H}_{2} \mathrm{O}$ and/or $\mathrm{Ni}\left(\mathrm{NO}_{3}\right)_{2} \cdot 6 \mathrm{H}_{2} \mathrm{O}$, followed by heat treatment in reducing $\left(\mathrm{H}_{2}+\mathrm{Ar}, \mathrm{N}_{2}\right)$ or inert $\left(\mathrm{N}_{2}, \mathrm{Ar}\right)$ atmosphere. The obtained CMK-3 carbon can be easily separated from the mixture by a magnet [61-64].

S. Zhang et al. [65] embeded well-dispersed $\mathrm{Ni}_{3} \mathrm{~S}_{2}$ into CMK-3 carbon by using $\mathrm{Ni}\left(\mathrm{NO}_{3}\right)_{2} \cdot 6 \mathrm{H}_{2} \mathrm{O}, \mathrm{H}_{2} \mathrm{SO}_{4}$ and sucrose for SBA-15 impregnation. The obtained material showed good electronic conductivity.

\subsubsection{Post-synthesis treatment}

Chemical modification of the CMK-3 surface can be also carried out by a post-synthesis approach. This modification method can be carried out by two ways. In one of them, pristine CMK-3 nanomaterial is treated by an oxidizing agent and the obtained carboxyl or hydroxyl groups are derived to other functionalities by the grafting method. In another way, synthesized CMK-3-type carbon is impregnated by a solution of a metal salt and the obtained solid is heated at high temperature in the inert atmosphere.

\subsubsection{Means of oxidation}

In the literature there are papers, in which treatment of hydrophobic CMK-3 material by oxidizing agents, such as $\mathrm{HNO}_{3}$ [6670], $\mathrm{H}_{2} \mathrm{O}_{2}[71,37], \mathrm{KMnO}_{4}$ [72] or $\left(\mathrm{NH}_{4}\right)_{2} \mathrm{~S}_{2} \mathrm{O}_{8}$ with $2 \mathrm{M} \mathrm{H}_{2} \mathrm{SO}_{4}[73,74]$ was performed. Different oxidation conditions: various concentrations of oxidizing agent, time and temperature of process were used by researchers. Aggressive oxidation conditions can lead to the collapse of ordered CMK-3 mesostructure.

\subsubsection{Incorporation of organic functionalities}

R. Chakravarti et al. [75] inserted aliphatic, cyclic or aromatic amines onto the surface of CMK-3-type carbon by C-N incorporating process. They formed more reactive surface organic groups by using 
$\mathrm{SOCl}_{2}$. M. Anbia and R. Dehghan [76] applied $\mathrm{SOCl}_{2}$ to increase efficiency of C-S bond formation between 2-amino-5-mercapto-1,3,4thiadiazole and carbon surface. J. He et al. [77] esterificated carboxyl surface groups of hexagonally ordered nanorods with 1-octanol in mxylol to prepare octyl-modified mesoporous carbon. Another research group [78] conducted nitration reaction of CMK-3 carbonaceous materials by using a mixture of $\mathrm{HNO}_{3}$ and $\mathrm{H}_{2} \mathrm{SO}_{4}$. Nitrated carbon was subsequently reduced by an aqueous solution of $\mathrm{NH}_{3}$ and $\mathrm{Na}_{2} \mathrm{~S}_{2} \mathrm{O}_{4}$. Ch. He and X. Hu [79] performed chemical modification of CMK-3-type carbon by gaseous $\mathrm{NH}_{3}$ treatment in a home-made thermal treatment system. Reactions with organosilane and carbon surface were performed to introduce amine- or thiolgroups onto CMK-3 surface [80-82].

Y.-D. Zou et al. [83] performed in situ phosphorylation of carbonaceous surface by treatment with concentrated $\mathrm{H}_{3} \mathrm{PO}_{4}$. R. Xing and Z. Fei [84] introduced methylamine or ethyldiamine onto the surface of CMK-3 carbons by chlorometylation (chloromethyl methyl ether and $\mathrm{AlCl}_{3}$ as a catalyst) and amination processes. The organic amine groups were successfully introduced inside the channels of mesoporous carbons without destroying the well-ordered 2D hexagonal mesostructure.

M. Anbia and A.H. Davijani [85] functionalized the CMK-3 material with L-cysteine. Other way of post-synthesis modification of CMK-3 is related to the polymerization process (aniline [86], methyl methacrylate [87]) inside the porous network of carbon or leading to coating of carbon by formated polymer (dopamine [88], acrylic acid [62]). Synthesized polymer can also be pyrolyzed onto the CMK-3type carbon surface [6].

\subsubsection{3. $\mathrm{Me}^{\mathrm{n}+}$ complex}

Functionalization of CMK-3 surface can be performed by incorporating of organic complexes of metal cation. $\mathrm{A} \mathrm{Cu}$ (II) chiral aza-bis(oxazoline) catalyst was anchored onto the carbon surface by A. R. Silva et al. [8]. W. Guo et al. [63] incorporated Ni(II) complex with 8-hydroxyquinoline into CMK-3 carbon. Schiff base complexes of $\mathrm{Cu}(\mathrm{II}), \mathrm{Co}(\mathrm{II}), \mathrm{Fe}(\mathrm{III})$ were successfully immobilized onto aminofunctionalized CMK-3 by X. Wang et al. [89]. 


\subsubsection{Metal species}

Some researchers introduced metallic nanoparticles such as $\mathrm{Pd}$ $[43,90]$, Co [43], Ni [91, 49], Pt [92, 48] onto the surface of CMK-3 by a wet impregnation procedure with a monodispersed colloidal solution or metal salt solution followed by reduction. Metal oxides were also inserted onto the surface of ordered mesoporous carbon $\left(\mathrm{ZrO}_{2}\right.$ [93], $\mathrm{ZnO}$ [94], $\mathrm{MnO}_{2}$ [95], $\left.\mathrm{Fe}_{2} \mathrm{O}_{3}[96,12]\right)$ by impregnation with a metal salt solution and treatment at high temperature. Introducing proper metal oxides into CMK-3 can provide carbon with magnetic properties [62]. Other metal compounds can also be used for CMK-3 surface modification, like spinel [9], alloys [16], sulfides [97], chlorides [98], metal/metal oxide mixtures [99] or oxyfluorides [10].

\subsection{Other means of modification}

Generally synthesized CMK-3 material is composed of an amorphous carbon with the low electrical conductivity and poor mechanical strength. Improvement of these properties is related to the application of graphitization methods. Q. Gao et al. [100] filled pores of SBA-15 silica with high polymerization degree aromatic polymers and p-toluene sulfonic acid acted as catalyst. An interesting approach was proposed by the group of prof. R. Ryoo [30]. Acenaphthene was used as a carbon source and Al-SBA-15 as a catalyst. Another way to gain graphitized carbon nanorods in the CMK-3 material was described by D. Nettelroth et al. [27], who proposed impregnation of the carbon by iron(III) nitrate nonahydrate solution at reflux conditions.

A.-H. Lu et al. [40] synthesized CMK-3-type carbon with a monolitic structure. The volume of the carbon precursor corresponded to twice the pore volume of the SBA-15 template in order to bind the individual $\mathrm{Si} / \mathrm{C}$ particles. A fine powder of $\mathrm{NaCl}$ acted as macropore generator.

H. Chen et al. [52] synthesized CMK-3-type carbon with developed microporosity by impregnation of SBA-15 silica mould with a carbon source (phenolic resin) and a silica source (TEOS). Y. Shi et al. [101] generated micropores in pristine CMK-3 carbon by $\mathrm{KOH}$ activation at high temperature in a nitrogen atmosphere. Z. He et al. [102] performed oxidation of CMK-3 carbonaceous material by $\mathrm{HNO}_{3}$ from liquid phase assisted with an ultrasonic activation. 


\section{PHYSICOCHEMICAL PROPERTIES AND APPLICATIONS}

CMK-3-type carbon contains hexagonally ordered (p6mm) nanorods interconnected by spacers, the presence of which was confirmed by scanning/transmission electron microscopy images and powder X-ray diffraction patterns (3 well-resolved peaks at low angles assigned to (100), (110) and (200) diffractions) (Fig. 7).
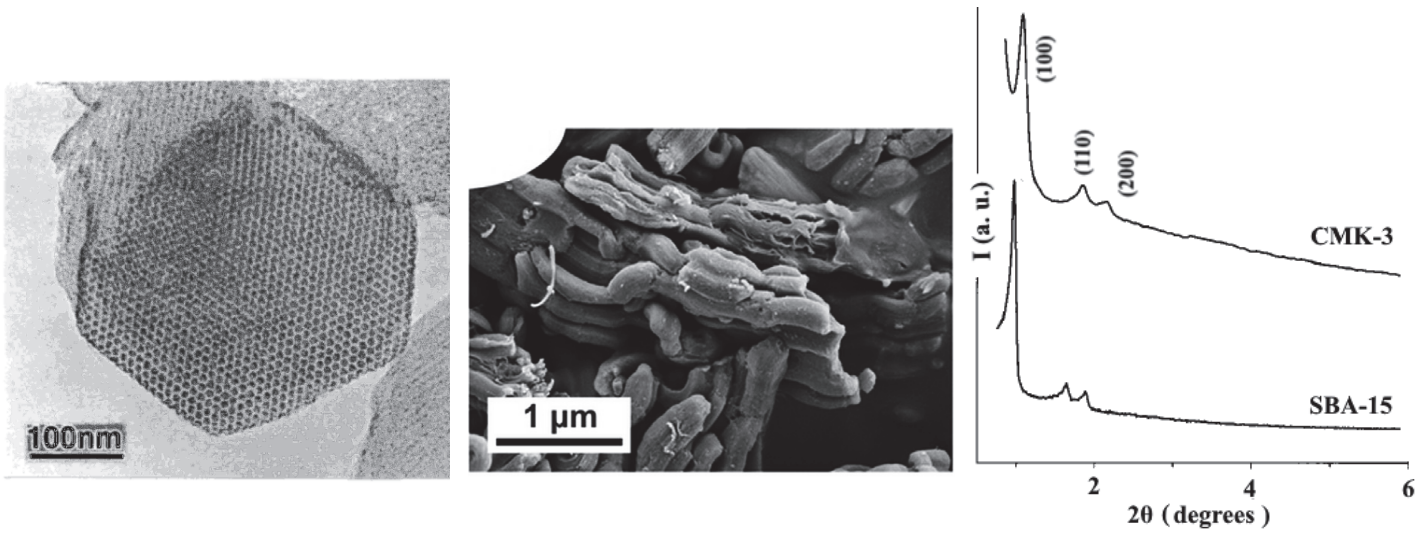

Fig. 7. TEM, SEM and XRD of CMK-3-type carbon [3, 82].

It constitutes the faithful reversed replica of the SBA-15 silica template. Thus the diameter of nanorods and mesopores in carbon material corresponds to the diameter of mesopores and wall thickness of the silica template, respectively. The nanorods are composed of amorphous carbon. This disordered nature of carbon frameworks is confirmed by the appearance of two broad Raman peaks at 1350 and $1590 \mathrm{~cm}^{-1}$. Nitrogen adsorption/desorption isotherm of CMK-3 carbon is classified as IV type (according to International Union of Pure and Applied Chemistry). Appearance of a hysteresis loop on the isotherm is connected with presence of mesopores in the carbon structure (Fig.8.). BET surface area of the CMK-3-type carbon is close to $1500 \mathrm{~m}^{2} \cdot \mathrm{g}^{-1}$. The CMK-3-type nanocarbon has a narrow pore size distribution $[3,82,30]$. The surface of the pristine CMK-3 material is characterized by a high degree of hydrophobicity and can be easily chemically modified [103]. Modification of the CMK-3 material leads to higher BET surface area [101], increased hydrophilicity degree of the CMK-3 surface, 
formation of potential active sites [75], better electric [54], magnetic [61] and catalytic [59] properties.
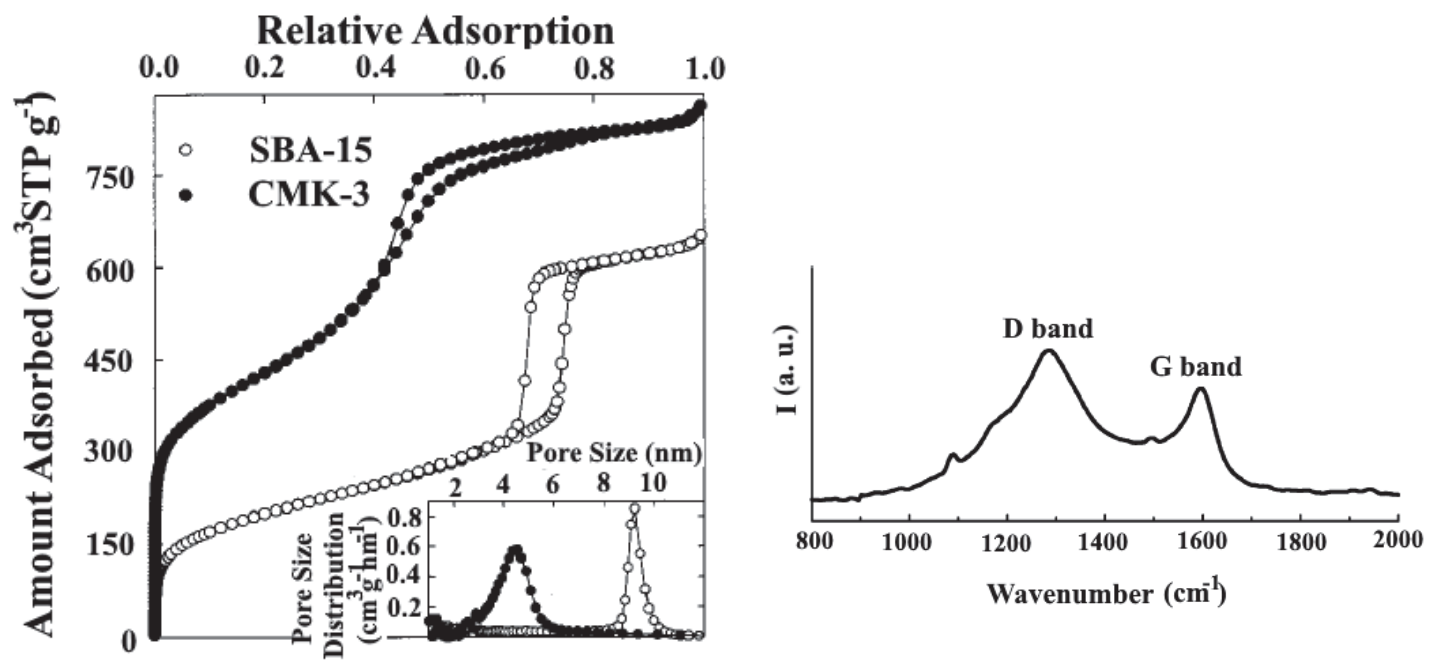

Fig. 8. Nitrogen adsorption/desorption isotherms and pore size distributions of SBA-15/CMK-3 material and Raman spectrum for CMK-3 [3, 30]

Chemically modified CMK-3-type carbon was studied as an adsorbent for remove of organic pollutants (1-Butyl-3-methylimidazolium chloride [67], chloramphenicol antibiotic [42], p-nitrophenol [64], phenol [77], reactive red 2 [79], active red X-3B [72] or resorcinol [44]) from wastewater, desulfurization of fuels (removing of dibenzothiophene [99]), extraction/pre-concentration of $\mathrm{N}$ nitrosamines before their determination [73] and solid and stable support for proteins [74]. W. -J. Jiang et al. [98] obtained the CMK-3 carbon modified by $\mathrm{Cu}(\mathrm{I})$, which was applied as a selective adsorbent of ethylene in the presence of ethane. CMK-3 carbon with a hydrophilic surface was used as an adsorbent for heavy metal ions (Cr(VI) [61, 96], U(VI) [83], $\mathrm{Hg}(\mathrm{II})$ [76, 94], $\mathrm{Pb}(\mathrm{II})$ [35, 63, 70, 80-82], Cd(II) [35, 62, 70, 81, 82, 85], Cu(II) [35, 63, 80-82], Zn(II) [81, 82], Sr(II) and Co(II) [63]) and phosphate anions [93]. M. Anbia with S. Salehi [86] and D. K. Singh et al. [41] used modified CMK-3 carbonaceous materials for effective $\mathrm{CO}_{2}$ adsorption. This type of nanocarbon was also investigated for $\mathrm{H}_{2}$ storage $[49,90]$.

Functionalized CMK-3 was used as a heterogeneous catalyst in oxygen reduction reactions (ORR) $[6,45,53,58]$, which are crucial for energy conversion and storage devices (fuel cells or batteries). 
This kind of carbonaceous material was also used as support for catalysts in different organic reactions: Knoevenagel condensation [84], enantioselective cyclopropanation [7, 8] and aziridination [7] of styrene, oxidative dehydrogenation of ethylbenzene [71] or propane [28, 57], aza-Michael reaction of amines to activated alkenes [75], styrene epoxidation [89], aerobic oxidation of 5-hydroxymethylfurfural to 2,5-furandicarboxylic acid in the aqueous phase [59], peroxymonosulfate activation for o-phenylphenol degradation [47], oxidation of benzyl alcohol [43], hydrogenation of carbonyl compounds [91], methanol oxidation reaction [56, 92], selective dehydration of fructose into 5-hydroxymethylfurfural [55], hydroconversion of $n$-heptane [48] or oxidation of ethylbenzene [46].

CMK-3-type carbons with a chemically modified surface were also used as components of lithium-ion batteries [9-11, 52, 65]. CMK3 materials ensured high discharge capacity and cycling stability of obtained batteries. F. Lai et al. [95] studied application of composite materials (N,S-doped CMK-3 with $\mathrm{MnO}_{2}$ nanosplotches) as ionic liquid-based symmetric supercapacitors, which exhibited a high specific capacitance and cyclic stability. These supercapacitors operated in a wide temperature range. M. Regiart et al. [15] used unmodified CMK-3 nanocarbon as a component of an electrochemical sensor for solid-phase microextraction and determination of triclosan in environmental samples. Addition of CMK-3 carbon to the electrode material increased its electron transfer and electrocatalytic activity. H. Zhou et al. [87] applied CMK-3 carbon modified by in situ polymerization and grafting of methyl methacrylate as a high performance microwave absorber.

Materials denoted as CMK-3 were also used for controlled release of drugs. Á. Sánchez-Sánchez et al. [51] synthesized CMK-3 carbon by nanocasting of a polyaramide precursor inside SBA-15 silica. The obtained nanocarbon was studied for a potential carriage and delivery of ibuprofen. Another research group [17] studied an ibuprofen delivery system based on poly(N-isopropyl acrylamide) functionalized ordered mesoporous carbon (CMK-3).

\section{CONCLUSIONS}

The wide spectrum of applications of CMK-3-type carbons is strictly related to the synthesis conditions. The rigid porous structure 
of the SBA-15 hard-template provides highly ordered mesopores inside the CMK-3 structure, which are related to the possibility of fast adsorption of large molecules and ions. Moreover, various chemical modifications of the carbon surface can lead to the formation of adsorptive/catalytic active sites, increasing of the electric conductivity or obtaining materials with magnetic properties (e. g. for easy separation from mixtures). Further development of modification strategies will certainly be related to new applications of this kind of carbon in different industries.

\section{REFERENCES}

[1] J. Rouquerol et al., Pure Appl. Chem., 66, 1739, (1994).

[2] R. Ryoo, S. H. Joo, S. Jun, J. Phys. Chem. B, 103, 7743, (1999).

[3] S. Jun et al., J. Am. Chem. Soc., 122, 10712, (2000).

[4] H. Chen, T. Yan, F. Jiang, J. Taiwan Inst. Chem. Eng., 45, 1842, (2014).

[5] Z. Ezzeddine et al., J. Mol. Liq., 223, 763, (2016).

[6] J. Xu et al., Nanotechnology, 28, 485701, (2017).

[7] H. Albuquerque et al., Polyhedron, 79, 315, (2014).

[8] A. R. Silva et al., Catal. Sci. Technol., 3, 659, (2013).

[9] T. Zhang et al., Carbon, 123, 717, (2017).

[10] D. Ni et al., J. Power Sources, 374, 166, (2018).

[11] F. Nitze et al., J. Power Sources, 317, 112, (2016).

[12] J. Hu et al., Carbon, 93, 903, (2015).

[13] V. C. Almeida et al., J. Mater. Chem. A, 2, 15181, (2014).

[14] D. Zhang, L. Lei, Y. Shang, J. Mater. Sci. Mater. Electron., 27, 3531, (2016).

[15] M. Regiart et al., Sens. Actuators B Chem., 232, 765, (2016).

[16] D. Xiang et al., The Analyst, 140, 644, (2015).

[17] S. Zhu et al., Mater. Chem. Phys., 126, 357, (2011).

[18] M. Ulfa, D. Prasetyoko, J. Phys. Conf. Ser., 1153, 012065, (2019).

[19] M. Enterría, J. L. Figueiredo, Carbon, 108, 79, (2016).

[20] M. Oszust, M. Barczak, A. Dąbrowski, in: Adsorbents and catalyst selected technologies and environment, (J. Ryczkowski, Ed.), Vol. 3., Uniwersytet Rzeszowski, Rzeszów, p. 53, 2012.

[21] P. F. Fulvio, S. Pikus, M. Jaroniec, J. Mater. Chem., 15, 5049, (2005).

[22] D. Zhao et al., J. Am. Chem. Soc., 120, 6024, (1998).

[23] S. K. Jana et al., Microporous Mesoporous Mater., 68, 133, (2004).

[24] Y. Zhai et al., J. Porous Mater., 15, 601, (2008).

[25] K. P. Gierszal et al., J. Phys. Chem. B, 109, 23263, (2005).

[26] J. Kim et al., Carbon, 75, 95, (2014). 
[27] D. Nettelroth et al., Phys. Status Solidi A, 213, 1395, (2016).

[28] A. Węgrzyniak et al., J. Porous Mater., 25, 687, (2018).

[29] C. Weinberger et al., The Sci. Function of Nanomater.: From Synthesis to Appl., 1183, 3, (2014).

[30] T.-W. Kim, I.-S. Park, R. Ryoo, Angew. Chem. Int. Ed., 42, 4375, (2003).

[31] P. Niebrzydowska et al., Carbon, 64, 252, (2013).

[32] K. Wu, Q. Liu, Appl. Surf. Sci., 379, 132, (2016).

[33] Y. Wang et al., J. Mater. Chem., 21, 14420, (2011).

[34] X. Wang et al., J. Mater. Sci., 45, 2958, (2010).

[35] M. Baikousi et al., J. Phys. Chem. C, 117, 16961, (2013).

[36] B. Zhang et al., Mater. Lett., 189, 317,(2017).

[37] A. Sánchez-Sánchez et al., Carbon, 62, 193, (2013).

[38] Y. Xia, R. Mokaya, Adv. Mater., 16, 1553, (2004).

[39] A. B. Fuertes, D. M. Nevskaia, J. Mater. Chem., 13, 1843, (2003).

[40] A.-H. Lu et al., Microporous Mesoporous Mater., 95, 187, (2006).

[41] D. K. Singh et al., Angew. Chem. Int. Ed., 55, 2032, (2016).

[42] A. T. Mohd Din, M. A. Ahmad, B. H. Hameed, Chem. Eng. J., 260, 730, (2015).

[43] V. Ravat, I. Nongwe, N. J. Coville, Microporous Mesoporous Mater., 225, 224, (2016).

[44] W. Shou et al., J. Appl. Polym. Sci., 133, 43426, (2016).

[45] M. Sevilla et al., RSC Adv., 3, 9904, (2013).

[46] R. Wang et al., IOP Conf. Ser. Mater. Sci. Eng., 207, 012012, (2017).

[47] J. Hou et al., Chemosphere, 197, 485,(2018).

[48] S. Said, New J. Chem., 42, 14517, (2018).

[49] S. Giraudet, Z. Zhu, Carbon, 49, 398, (2011).

[50] X. Gao et al., Adv. Funct. Mater., 26, 6649, (2016).

[51] Á. Sánchez-Sánchez et al., Carbon, 94, 152, (2015).

[52] H. Chen et al., Electrochimica Acta, 214, 231, (2016).

[53] T. Jiang et al., Appl. Catal. B Environ., 189, 1, (2016).

[54] D. Zhang et al., J. Mater. Chem. A, 1, 7584, (2013).

[55] B. Karimi et al., ACS Appl. Mater. Interfaces, 7, 19050, (2015).

[56] Y. Chang et al., Carbon, 87, 424, (2015).

[57] R. Goyal et al., J. Mater. Chem. A, 4, 18559, (2016).

[58] S.-H. Liu et al., J. Mater. Chem., 21, 12489, (2011).

[59] F. Kerdi et al., Appl. Catal. Gen., 506, 206, (2015).

[60] P. F. Fulvio et al., Eur. J. Inorg. Chem., 2009, 605, (2009).

[61] L. Tang et al., Chem. Eng. J., 239, 114, (2014).

[62] G. Zeng et al., Chem. Eng. J., 259, 153, (2015).

[63] W. Guo et al., J. Ind. Eng. Chem., 21, 340, (2015).

[64] Y. Zhou et al., J. Hazard. Mater., 333, 80, (2017).

[65] S. Zhang et al., Chem. Eng. J., 314, 19, (2017).

[66] J. Lang et al., J. Power Sources, 204, 220, (2012). 
[67] L. Zhang et al., Appl. Surf. Sci., 440, 821, (2018).

[68] H. Li et al., Microporous Mesoporous Mater., 96, 357, (2006).

[69] P. A. Bazuła et al., Microporous Mesoporous Mater., 108, 266, (2008).

[70] R. Moreno-Tovar, E. Terrés, J. R. Rangel-Mendez, Appl. Surf. Sci., 303, 373, (2014).

[71] P. Janus et al., Catal. Today, 235, 201, (2014).

[72] X. Dong et al., Mater. Lett., 65, 2486, (2011).

[73] M. Lashgari, H. K. Lee, J. Colloid Interface Sci., 481, 39, (2016).

[74] A. Vinu et al., J. Mater. Chem., 17, 1819, (2007).

[75] R. Chakravarti et al., ChemCatChem, 6, 2872, (2014).

[76] M. Anbia, R. Dehghan, J. Environ. Sci., 26, 1541, (2014).

[77] J. He et al., Microporous Mesoporous Mater., 121, 173, (2009).

[78] M. Leżańska et al., Mater. Chem. Phys., 149, 539, (2015).

[79] C. He, X. Hu, Adsorption, 18, 337, (2012).

[80] H. Hamad et al., Mater. Chem. Phys., 178, 57, (2016).

[81] K. Michalak-Zwierz et al., Adsorpt. Sci. Technol., 33, 663, (2015).

[82] M. Barczak et al., Microporous Mesoporous Mater., 211, 162, (2015).

[83] Y.-D. Zou et al., J. Radioanal. Nucl. Chem., 306, 515, (2015).

[84] R. Xing, Z. Fei, J. Chin. Chem. Soc., 61, 1093, (2014).

[85] M. Anbia, A. H. Davijani, Chem. Eng. J., 223, 899, (2013).

[86] M. Anbia, S. Salehi, J. Polym. Res., 23, 124, (2016).

[87] H. Zhou et al., Nanoscale, 5, 12502, (2013).

[88] Y. Song et al., Chem. Mater., 28, 5013, (2016).

[89] X. Wang et al., Microporous Mesoporous Mater., 221, 58, (2016).

[90] D. Giasafaki et al., Carbon, 98, 1, (2016).

[91] D. Kim et al., Eur. J. Inorg. Chem., 2016, 3469, (2016).

[92] L. Calvillo et al., J. Power Sources, 169, 59, (2007).

[93] X. Ju et al., Microporous Mesoporous Mater., 230, 188, (2016).

[94] G. Zolfaghari et al., J. Hazard. Mater., 192, 10, (2011).

[95] F. Lai et al., Adv. Funct. Mater., 28, 1801298, (2018).

[96] M. Baikousi et al., Langmuir, 28, 3918, (2012).

[97] S. Liu, W. Lei, Y. Liu, Chem. Eng. J., 356, 10, (2019).

[98] W.-J. Jiang et al., Sep. Sci. Technol., 48, 968, (2013).

[99] J. Cheng et al., Microporous Mesoporous Mater., 212, 9, (2015).

[100] Q. Gao et al., J. Porous Mater., 20, 983, (2013).

[101] Y. Shi, X. Zhang, G. Liu, Fuel, 158, 565, (2015).

[102] Z. He et al., J. Mater. Sci., 52, 2422, (2017).

[103] H. Darmstadt et al., Carbon, 40, 2673, (2002). 
